\title{
Petrology and geochemistry of Northwest Africa 5480 diogenite and evidence for a basin-forming event on Vesta
}

\author{
A. YAMAGUCHI ${ }^{1,2 *}$ J. A. BARRAT ${ }^{3}$, N. SHIRAI ${ }^{4}$, and M. EBIHARA ${ }^{1,4}$ \\ ${ }^{1}$ National Institute of Polar Research, Tachikawa, Tokyo 190-8518, Japan \\ ${ }^{2}$ Department of Polar Science, School of Multidisciplinary Science, SOKENDAI (The Graduate \\ University for Advanced Studies), Tokyo 190-8518, Japan \\ ${ }^{3}$ U.B.O.-I.U.E.M., CNRS UMR 6538, Place Nicolas Copernic, 29280 Plouzané Cedex, France \\ ${ }^{4}$ Graduate School of Science, Tokyo Metropolitan University, Hachioji, Tokyo 192-0397, Japan \\ *Corresponding author. E-mail: yamaguch@nipr.ac.jp
}

(Received 01 September 2014; revision accepted 17 April 2015)

\begin{abstract}
We performed a petrological and geochemical study of an olivine diogenite, Northwest Africa (NWA) 5480. NWA 5480 is a crystalline stone, but shows a heterogeneous texture. Olivine aggregates and grains of olivine and chromite display resorption textures set in a crystalline pyroxene matrix. Large olivine aggregates are penetrated by pyroxene matrix. Flow textures are observed near olivine aggregates. Olivine, chromite, and pyroxene show minor chemical zoning, implying relatively rapid cooling. NWA 5480 contains a significant amount of platinum group elements with chondritic relative proportions. All this evidence supports that NWA 5480 is an impact-melt breccia from a target composed of olivine and pyroxene-rich lithologies. Such impact melt would have formed by melting crustal materials, possibly during one of the impacts that formed the South Pole basins on Vesta.
\end{abstract}

\section{INTRODUCTION}

The HED (howardite, eucrite, diogenite) meteorites are the largest group of achondrites, representing approximately $5.5 \%$ of all falls (statistics from Meteoritical Bulletin Database 2014). They are generally considered to be derived from the regolith and crustal lithologies of asteroid 4 Vesta (e.g., McCord et al. 1970; Binzel and $\mathrm{Xu}$ 1993), which is the only surviving differentiated protoplanet (i.e., with a crust, mantle, and metallic core) in the solar system (e.g., Russell et al. 2012).

Recently, Vesta has been extensively explored by the Dawn spacecraft, which provided a wealth of data and images. Thus, Vesta is one of a small number of telluric bodies that can be investigated both with rock samples and remote sensing observations, other examples being the Moon, Mars, and asteroid Itokawa. Indeed, the observations made by Dawn not only allow description of the morphology of the body, but provide strong constraints on its surface composition, its impact history, its internal structure, and a geological framework for the study of HED meteorites (e.g., De Sanctis et al. 2012; Russell et al. 2012; Schenk et al. 2012).

Although Dawn has considerably improved our knowledge of Vesta, the mantle of this body is still apparently not exposed. The giant impacts that formed Veneneia and Rheasilvia, the two overlapping basins in the South Pole of the body, have deeply excavated the crust of the body (Schenk et al. 2012), possibly to a depth of at least $80 \mathrm{~km}$ (Jutzi et al. 2013; Clenet et al. 2014). However, no outcrops of olivine-rich lithologies have yet been detected in the two South Pole basins. Furthermore, olivine-rich HED meteorites are scarce, and are generally thought to be from diogenitic lithologies (Mittlefehldt 2015).

The petrology of diogenites is at present a central question for the understanding of the differentiation of Vesta (e.g., Mittlefehldt 2015). These rocks are clearly orthopyroxene-rich cumulates, but their exact significance remains a matter of debate. In particular, a question remains whether they are derived from a deep global layer (e.g., Takeda 1997; McSween et al. 2013), or from intrusions within the crust (e.g., Mittlefehldt 1994; Barrat 
et al. 2008, 2010; Shearer et al. 2010; Yamaguchi et al. 2011). Their parental melts are unknown, their genetic links with the eucritic lithologies are controversial (e.g., Mandler and Elkins-Tanton 2013; Barrat and Yamaguchi 2014), and their chronology was not resolved, but they could be younger than the eucrites on the basis of petrologic and geochemical considerations (Barrat et al. 2010; Yamaguchi et al. 2011). Some of them display rather high levels of platinum group element (PGE) concentrations that have been attributed to late accretion of the body (Dale et al. 2012; Day et al. 2012).

Here we examine in depth the petrology of Northwest Africa (NWA) 5480, a unique diogenite rich in olivine (olivine diogenite or harzburgite) (Beck and McSween 2010), which was briefly described by Irving et al. (2009). Its major and trace element abundances were previously reported by Barrat et al. (2010) and Day et al. (2012). NWA 5480 has a normal HED oxygen isotopic composition (Day et al. 2012; Greenwood et al. 2014). However, Tkalcec et al. (2013) and Tkalcec and Brenker (2014) suggested that this meteorite did not form as a simple cumulate rock and implied that this rock has recorded mantle processes on the basis of fabric analysis of an olivine-rich portion. Moreover, it is one of the diogenites displaying the highest PGE abundances (Day et al. 2012). We have made a detailed petrographic study of this meteorite and redetermined its PGE abundances. Our results demonstrate that this meteorite is not a mantle rock, but was produced by a large impact into a heterogeneous diogenitic target.

\section{SAMPLES AND ANALYTICAL TECHNIQUES}

We obtained three slabs of NWA 5480 (3.57, 4.91, and $2.64 \mathrm{~g}$ ) from the owner of the main mass. The 3.57 and $4.91 \mathrm{~g}$ slabs show a mottled texture of dark and gray zones indicating a mixture of pyroxene and olivine. The $2.64 \mathrm{~g}$ slab is composed of large dark olivine-rich and light pyroxene-rich portions. Polished thin sections (PTSs) (11 and 22) were carefully prepared from the 4.91 and 2.64 gram slabs, respectively, in order to show representative textures. They were examined with an optical microscope, scanning electron microscopes (JEOL JSM5900LV and 7100F) equipped with an energy dispersive spectrometer (Oxford AZtec Energy) at National Institute of Polar Research, Tokyo (NIPR). Minerals were analyzed with the NIPR JXA 8200 electron microprobe analyzer (EPMA) using natural and synthetic standards at $15 \mathrm{KeV}$ and $30 \mathrm{nA}$ using a focused beam. Peak counting times of $30 \mathrm{~s}$ were used. Data were reduced with ZAF correction program. We also studied other olivine diogenites, Asuka (A)-881548, and -881377, and NWA 1877, and an impact-melt breccia of LL chondrites, Yamato (Y)-790964 for petrologic comparison (Yamaguchi et al. 1998, 2011).

A chip of NWA $5480(1.841 \mathrm{~g})$ taken from the $4.91 \mathrm{~g}$ slab (mixture of pyroxene and olivine) was powdered with a clean agate mortar and pestle at Tokyo Metropolitan University (TMU). The abundances of PGE (Ru, Rh, Pd, Ir, and Pt) were determined using an isotope dilution method and an external calibration method employing inductively coupled plasma-mass spectrometer (ICP-MS) combined with a nickel sulfide fire assay (Shirai et al. 2003). The sample was mixed with sodium tetraborate, sodium carbonate, nickel powder, sulfur, silica, and a mixture of PGE enriched spike. This mixture was then transferred into a crucible and heated at $850{ }^{\circ} \mathrm{C}$ for $20 \mathrm{~min}$ followed by $1000{ }^{\circ} \mathrm{C}$ for $20 \mathrm{~min}$ in a muffle furnace. After fusion, the NiS bead was separated from the slag and dissolved in $60 \mathrm{ml}$ of $6 \mathrm{M} \mathrm{HCl}$. After complete dissolution, the resulting solution was passed through a $0.2 \mu \mathrm{m}$ polytetrafluoroethylene (PTFE) membrane filter, which eliminated most of the dissolved $\mathrm{Ni}$. The precipitate containing PGE sulfides and undissolved $\mathrm{NiS}$ was dissolved in $\mathrm{HCl}$ with hydrogen peroxide. After complete dissolution of the PGE sulfides and undissolved NiS, the solution obtained was passed through $1 \mathrm{ml}$ of cation exchange resin (AG50X-8, 100 200 mesh) in order to remove the remaining $\mathrm{Ni}$ from solution. ${ }^{99} \mathrm{Ru} /{ }^{101} \mathrm{Ru}, \quad{ }^{105} \mathrm{Pd} /{ }^{106} \mathrm{Pd}, \quad{ }^{191} \mathrm{Ir} /{ }^{193} \mathrm{Ir}$, and ${ }^{196} \mathrm{Pt} /{ }^{195} \mathrm{Pt}$ ratios were used in the isotope dilution. Because $\mathrm{Rh}$ is a monoisotopic element, its abundances were determined using a calibration method with internal standard elements (In and Tl). Chemical recoveries of $\mathrm{Rh}$ were corrected using recovery values for $\mathrm{Ru}$ and $\mathrm{Pd}$ (calibration method data/isotope dilution data).

\section{RESULTS}

\section{Textures}

NWA 5480 is composed of olivine; orthopyroxene; and minor amounts of chromite, FeNi-FeS, and augite (Irving et al. 2009; Day et al. 2012; Tkalcec et al. 2013; Tkalcec and Brenker 2014) (Fig. 1). This diogenite is a heterogeneous rock; the modal abundances and grain sizes of olivine and pyroxene differ widely in both PTSs. PTS11 is a relatively homogeneous pyroxene-rich matrix $($ PTS11; $1.6 \times 1.3 \mathrm{~cm})$, whereas PTS22 contains a portion of a large olivine aggregate $(>1.5 \mathrm{~cm})$ and pyroxene-rich matrix (about $1 / 3$ of the PTS) (PTS22; $1.7 \times 1.5 \mathrm{~cm})($ Fig. 1a).

The PTSs of NWA 5480 show irregular or subrounded olivine grains set in a pyroxene-rich matrix, mostly composed of orthopyroxene. In PTS11, large 

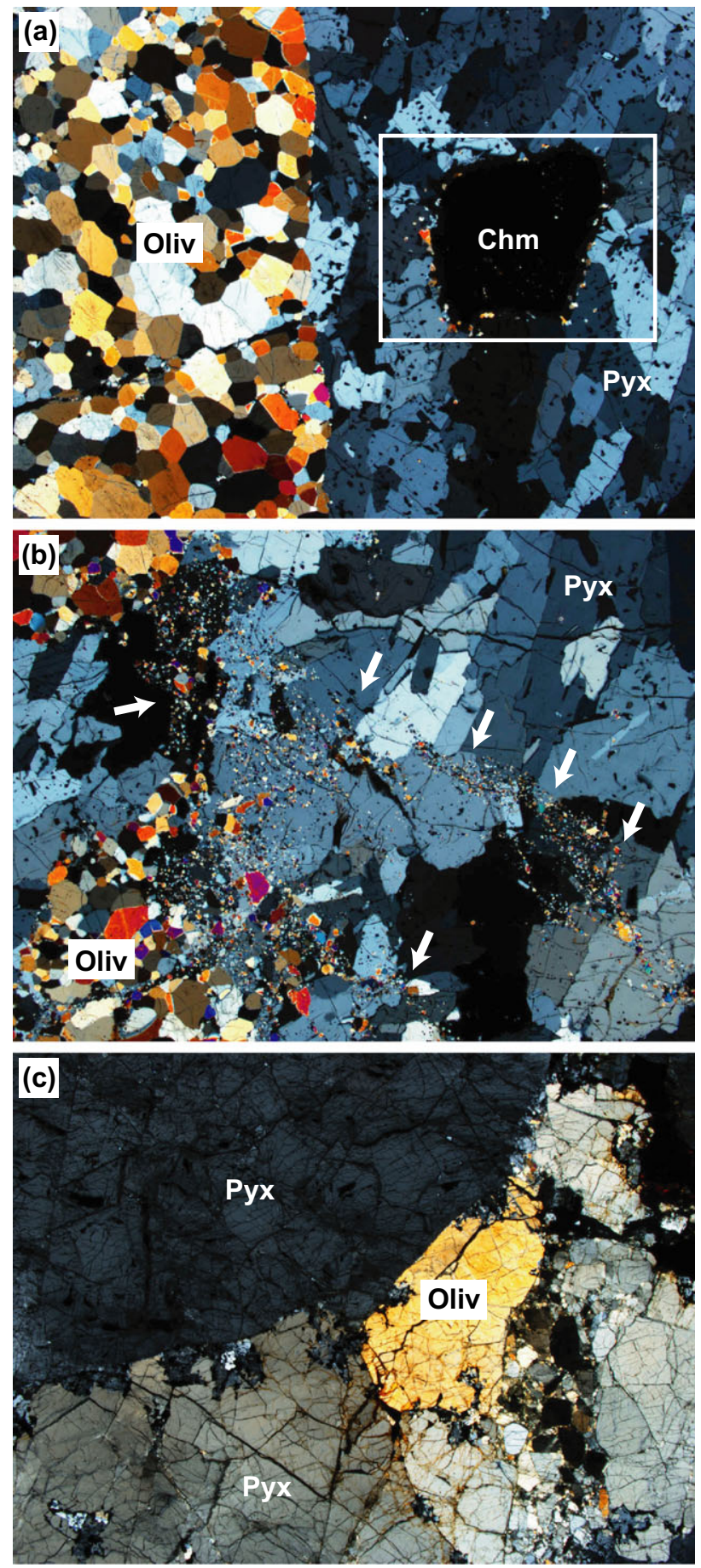

Fig. 1. a) Photomicrograph of a large olivine aggregate (left) attached to coarse-grained matrix of pyroxene (right) in NWA 5480 (crossed polarized light). Image in white box is shown in Fig. 2d. b) Photomicrograph of a portion showing lines of tiny olivine granules forming a flow texture (white arrows) in NWA 5480 (crossed polarized light). Note that the lines of granules intersect coarse pyroxene grains. c) Photomicrograph of a typical olivine diogenite, A-881548, which preserves an original coarse-grained texture composed of olivine and pyroxene (several $\mathrm{mm}$ in size). Right part is slightly brecciated. Widths of the all images are about $4.7 \mathrm{~mm}$. and relatively small olivine grains $(<1 \mathrm{~mm}$ in size and $\sim 10-50 \mu \mathrm{m}$ in size) are densely scattered throughout the PTS. In most cases, fine granules of olivine are attached to the edges of the larger olivine grains. However, in PTS22, there are less abundant olivine grains in the matrix except near the large olivine aggregates (see below). Near the large olivine grains, fine clusters of olivine granules are aligned, forming a flow texture (or a schlieren texture) (Fig. 1b).

Olivine aggregates show a granular texture $(\sim 50$ $300 \mu \mathrm{m}$ ) with curved boundaries and well-developed $120^{\circ}$ triple junctures (Fig. 1a). Fe-FeS, chromites, and minor augite grains are present along boundaries of the olivine. Augite contains vermicular chromite. There are very fine $(<1 \mu \mathrm{m})$ opaque granules, or dusty inclusions (mainly FeNi-FeS and chromite) in or across olivine grains. In PTS22, the boundaries between the large olivine grain and the matrix is sharp, curved, or shows complex textures. In some cases the matrix pyroxene penetrates into the olivine grain, forming veins $(>50$ $100 \mu \mathrm{m}$ thick) (Figs. 2a and 2b). There are many olivine granules in pyroxenes in such areas (see above).

Chromite occurs as irregular, large grains, aggregates $(0.3-1.5 \mathrm{~mm})$, or mixtures of the two (Figs. 1a and 2d). It also forms very fine stringers (a few $\mu \mathrm{m}$ thick) interstitially between pyroxene and olivine. Some large chromite grains contain thin irregular veins of pyroxene which enclose fine-grained, euhedral chromite (10-50 $\mu \mathrm{m}$ in size) (Figs. $2 \mathrm{~d}$ and $2 \mathrm{e}$ ). Large chromite grains have rims consisting of fine granules of olivine and chromite.

The matrix displays an interlocking texture composed of elongated pyroxene grains (Fig. 1). The two PTSs show different pyroxene grain sizes. Pyroxene in PTS22 $(\sim 2-3 \times 0.2-1 \mathrm{~mm})$ is coarser grained than in PTS11 $(\sim 0.3-1 \mathrm{~mm})$.

There are many irregular to subrounded holes $(\sim 20$ $100 \mu \mathrm{m})$ in the two PTSs, which may be vesicles or phases that were weathered out (FeS?). It is unlikely that these holes are artifacts formed during preparation of PTSs because they are filled with epoxy. Olivine and pyroxene show sharp optical extinction, indicating little shock effects after crystallization (or recrystallization) of this rock.

\section{Mineral Chemistry}

Major element compositions of olivine $\left(\mathrm{Fa}_{25.6-28.9}\right)$, pyroxene $\left(\mathrm{Wo}_{1.2-2.5} \mathrm{En}_{73.8-75.8} \mathrm{Fs}_{22.8-24.5}\right)$, and chromite (Usp ${ }_{1.7-2.5} \mathrm{Sp}_{14.0-18.9} \mathrm{Chm}_{78.9-84.1}$, where Usp is ulvöspinel, $\mathrm{Sp}$ is spinel, and $\mathrm{Chm}$ is chromite) are within the ranges of diogenites and olivine diogenites (e.g., Fowler et al. 1994; Mittlefehldt 1994; Beck and McSween 2010; Shearer et al. 2010; Yamaguchi et al. 2011) (Figs. 3-6; 


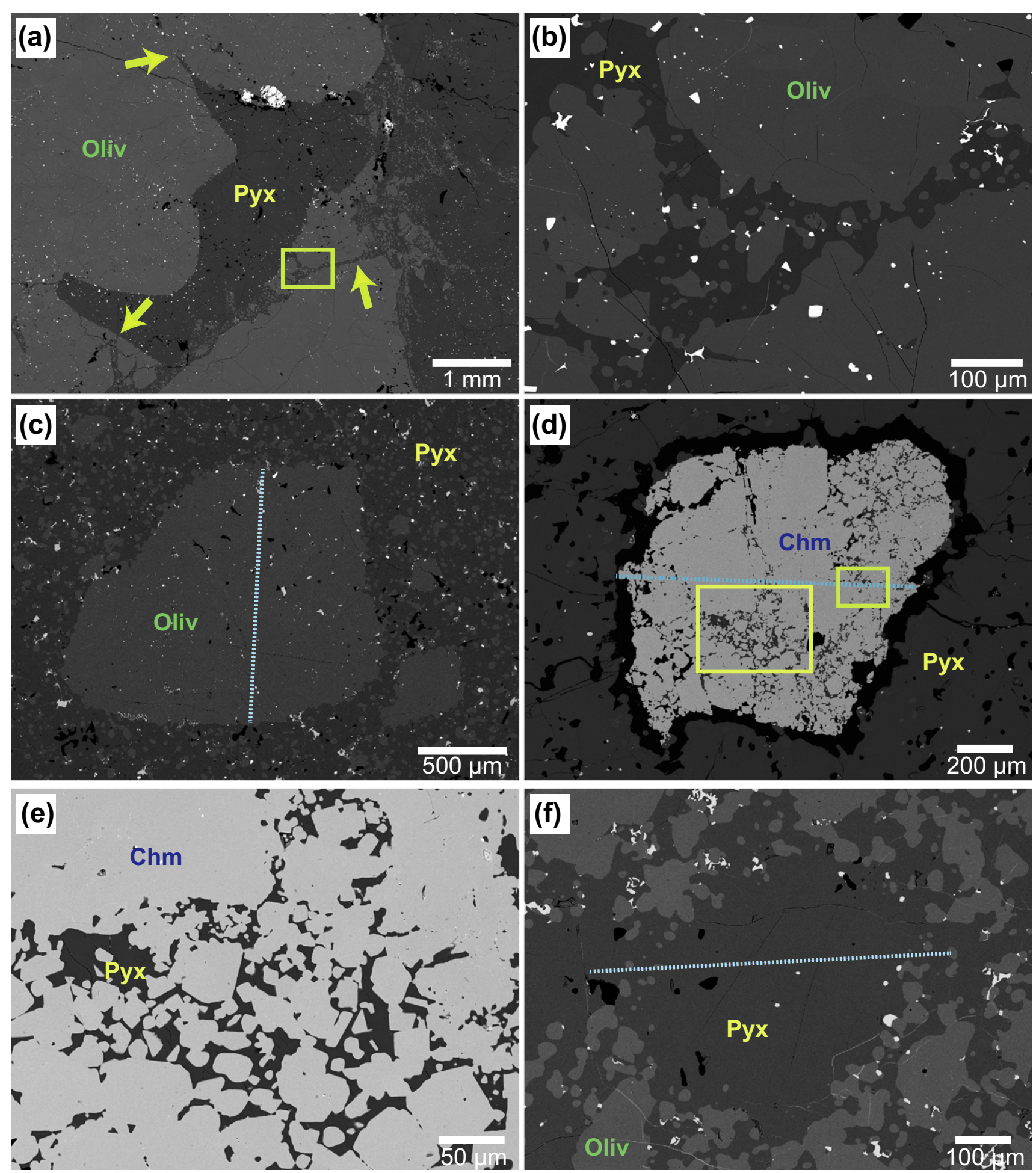

Fig. 2. a) Backscattered electron image (BEI) of an olivine aggregate (Oliv) and pyroxene (Pyx). Note that pyroxene veins intersect or intrude into the olivine aggregate (arrows). b) Enlarged portion of a box in (a). There are small olivine granules in veins and attached to olivine aggregate. c) BEI of subrounded olivine grain (Oliv) pyroxene matrix (Pyx). There are small olivine granules around the olivine grain. d) BEI of a chromite grain showing an irregular shape, intruded by pyroxene veins (box in Fig. 1a). e) Enlarged portion of a yellow square in (e). Pyroxene veins are filled with euhedral chromite crystals. f) Pyroxene microphenocryst surrounded by finer olivine and pyroxene. Dotted lines in (c) and (f) refer to locations for compositional profiles in Figs. 3 and 5, respectively. In all images, dark-gray is pyroxene, light-gray is olivine, white is chromite or FeS, and black is epoxy filled with cracks. 

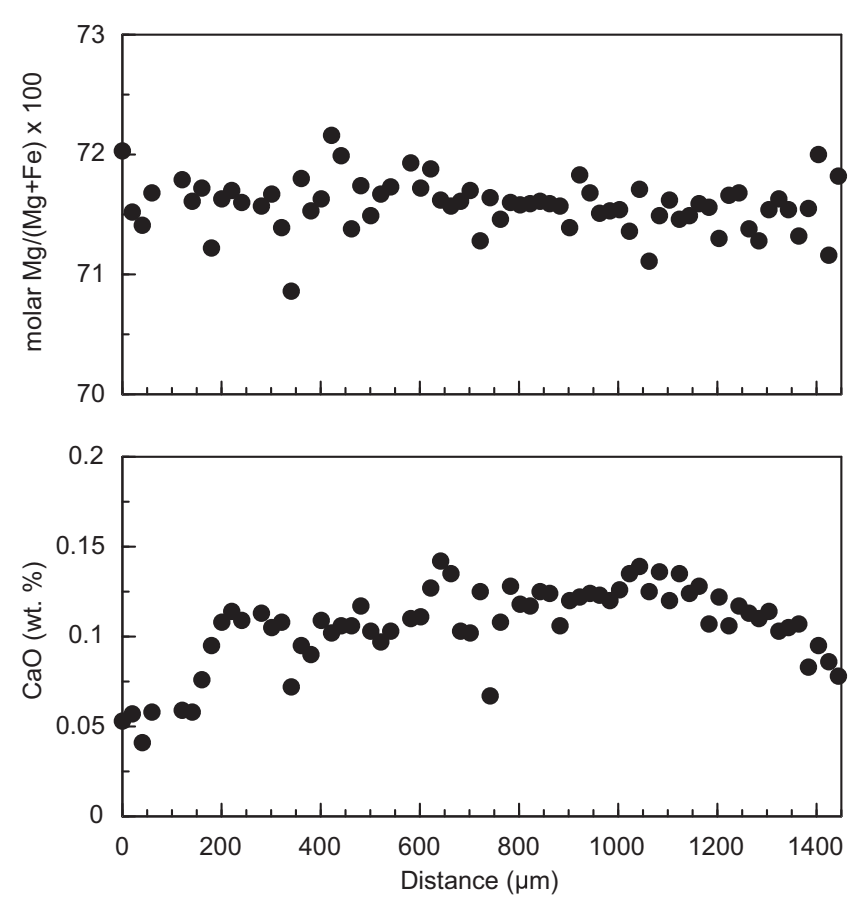

Fig. 3. Compositional profiles across an olivine grain. $\mathrm{Mg} / \mathrm{Fe}$ zoning is not observed. The core of the olivine has a higher $\mathrm{CaO}$ abundance $(\sim 0.1-0.15 \mathrm{wt} \%)$ than the $\operatorname{rim}(\sim 0.05 \mathrm{wt} \%)$. Similar chemical relations are observed in ordinary chondrite impact-melt rocks (Yamaguchi et al. 1998) and in pallasites (Miyamoto 1997). The locations of the profiles are shown in Fig. 2c.

Table 1). Olivine grains show zoning of $\mathrm{CaO}$ near the rims (from $0.04-0.08 \mathrm{wt} \%$ to $0.10-0.12 \mathrm{wt} \%$ ) (Fig. 3). $\mathrm{Mg} \#$ values $(=$ molar $\mathrm{Mg} /[\mathrm{Mg}+\mathrm{Fe}] \times 100)$ and the abundances of $\mathrm{Cr}_{2} \mathrm{O}_{3}$ and $\mathrm{Al}_{2} \mathrm{O}_{3}$ are almost constant. The $\mathrm{CaO}$ content of olivine in the matrix $(0.04-0.08 \mathrm{wt} \%)$ is less than that displayed by the large olivine grains (0.06-0.12 wt\%) (Fig. 4).

Chromite has significant chemical variation ( $\mathrm{Usp}_{1.7-2.4}$ $\mathrm{Sp}_{15.1-18.9} \mathrm{Chm}_{78.9-83.0}$, Fe\# $[=$ molar $\mathrm{Fe} /(\mathrm{Fe}+\mathrm{Mg}) \times$ $100=78.9-83.0]$ in PTS11, and Usp $1.8-2.5 \mathrm{Sp}_{14.0-17.9}$ $\left.\mathrm{Chm}_{79.6-84.1}[\mathrm{Fe} \#=69.6-80.2]\right)$ in PTS22. We found several large chromite grains (or aggregates) having chemical zoning. Sp and $\mathrm{Mg \#}$ values decrease from core to rim (Sp 17.4-16, $\mathrm{Mg} \#=\sim 70-74)$ (Fig. 5). Compositions of chromite grains in PTS11 range from $\mathrm{Usp}_{2.3} \mathrm{Sp}_{16.1}$ $\mathrm{Chm}_{81.7} \quad(\mathrm{Fe} \#=76.2) \quad$ to $\mathrm{Usp}_{2.1} \mathrm{Sp}_{15.9} \mathrm{Chm}_{82.0} \quad(\mathrm{Fe} \#=$ 78.0 ), and those in PTS22 range from $\mathrm{Usp}_{2.0} \mathrm{Sp}_{15.9}$ $\mathrm{Chm}_{82.1} \quad(\mathrm{Fe} \#=69.9) \quad$ to $\quad \mathrm{Usp}_{2.0} \mathrm{Sp}_{16.0} \mathrm{Chm}_{81.9}$ $(\mathrm{Fe} \#=74.5)$.

Matrix pyroxene also has chemical zoning with respect to $\mathrm{CaO}$ and $\mathrm{Al}_{2} \mathrm{O}_{3}$. Abundances of $\mathrm{CaO}$ and $\mathrm{Al}_{2} \mathrm{O}_{3}$ increase toward the rims but $\mathrm{Mg} \#$ values show no resolvable changes (Fig. 6). We could not find any chemical differences among pyroxenes from PTS11 and 22 nor in pyroxene inside chromite grains.

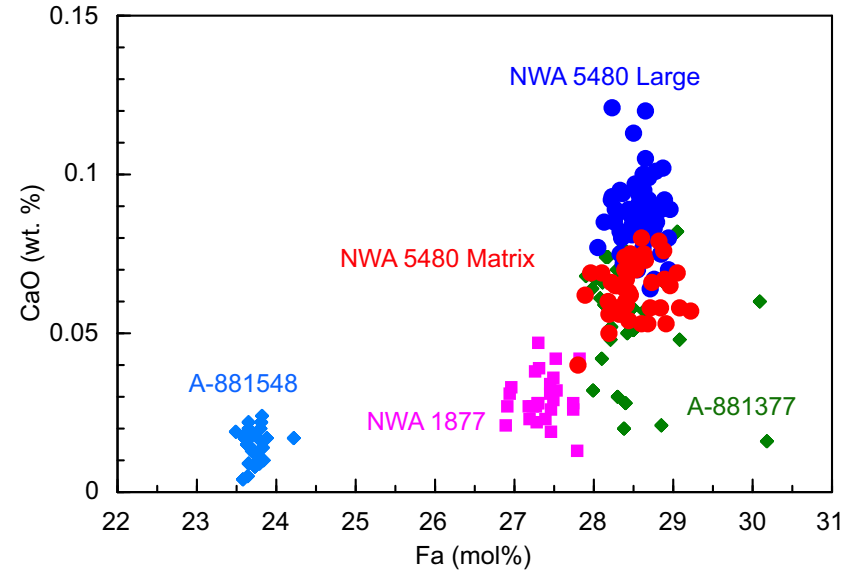

Fig. 4. Fa (molar $\mathrm{Fe} /[\mathrm{Fe}+\mathrm{Mg}] \times 100)$ versus $\mathrm{CaO}$ abundances in olivine from NWA 5480 and other olivine diogenites. In general, olivines in olivine diogenites have low $\mathrm{CaO}$ $(<\sim 0.07 \mathrm{wt} \%)$. A-881377 has a range of compositions because this diogenite is unequilibrated (Yamaguchi et al. 2011). Large olivine grains ("Large") and assemblages in NWA 5480 have high $\mathrm{CaO}$ in contrast to small granules in the pyroxene matrix ("Matrix").

\section{Platinum Group Element (PGE) Abundances}

PGE data obtained from the mixture of pyroxene and olivine show chondritic distributions in NWA 5480 and are present in moderate abundances $\left(\sim 10^{-3} \times \mathrm{CI}\right)$ (Fig. 7; Table 2). Our results are similar to those obtained by Day et al. (2012), and are in the range of diogenites (Dale et al. 2012; Day et al. 2012), but are much higher than those of uncontaminated diogenites such as Dhofar 700 and NWA 1877 (Dale et al. 2012).

\section{DISCUSSION}

It is widely accepted that diogenites are cumulate rocks formed in magma chambers or a magma ocean mainly on the basis of geochemical considerations (e.g., Mittlefehldt 1994; Barrat et al. 2008). Low-Ca pyroxene (orthopyroxene or pigeonite) crystallized from magma accumulated on the bottom of chambers due to density segregation. Such processes would have been very slow producing coarse-grained textures as observed in terrestrial layered intrusions (e.g., Jackson 1961). Although primary textures of many diogenites were obliterated by brecciation and recrystallization, some diogenites preserve original igneous textures. For example, olivine diogenite A-881548 shows a very coarse-grained texture (Fig. 1c). Y-74097 is a recrystallized rock but shows a remnant coarse-grained texture (Yamaguchi et al. 2011).

NWA 5480 is unbrecciated, but has heterogeneous crystalline texture, indicating that it is not a simple 

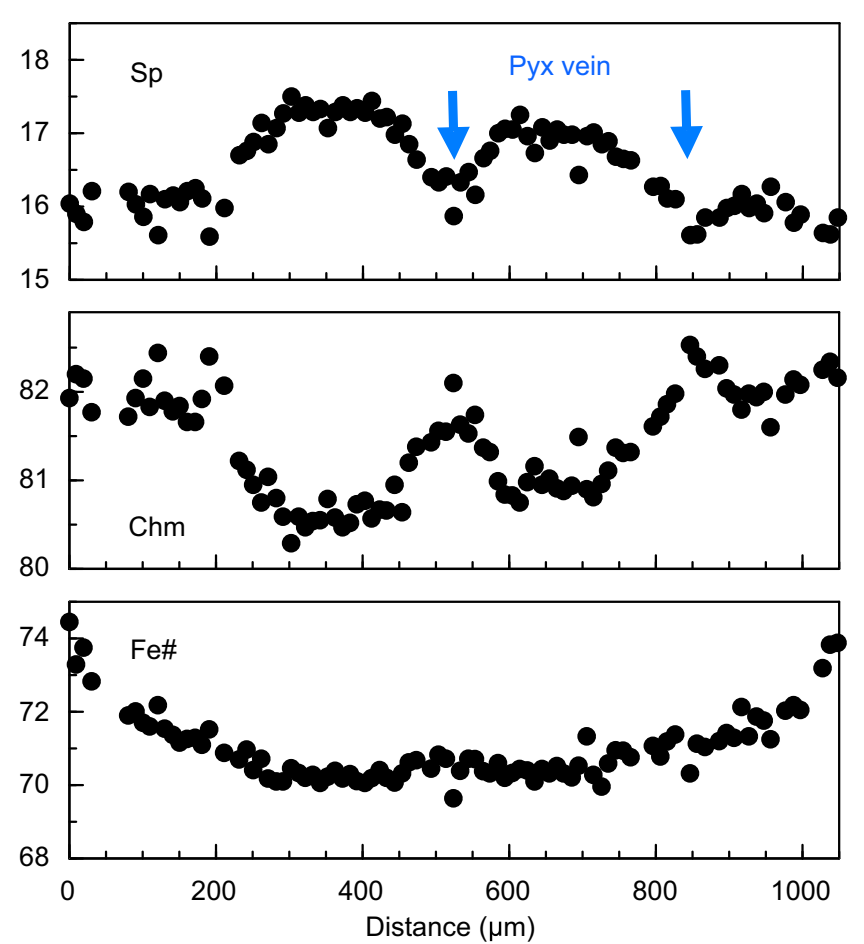

Fig. 5. Compositional profiles of a large chromite grain (Figs. 1a and $2 \mathrm{~d})$. The $\mathrm{Sp}(=$ molar $\mathrm{Al} /[2 \mathrm{Ti}+\mathrm{Al}+\mathrm{Cr}] \times 100)$ and $\mathrm{Chm}(=$ molar $\mathrm{Cr} /[2 \mathrm{Ti}+\mathrm{Al}+\mathrm{Cr}] \times 100)$ values, as well as $\mathrm{Fe \#}(=$ molar $\mathrm{Fe} /[\mathrm{Mg}+\mathrm{Fe}] \times 100)$, show normal igneous zoning. Valleys on the Sp profile (blue arrows) (peaks on the $\mathrm{Chm}$ profile) refer to new euhedral chromites formed along pyroxene veins ("Pyx veins"). The locations of these profiles are shown in Fig. $2 d$.

cumulate rock. Abundances and sizes of olivine grains and aggregates vary widely. Olivine and chromite grains and aggregates with irregular or rounded outlines are set in a pyroxene-rich matrix. In some cases these grains and aggregates are penetrated by pyroxene veins (Figs. 2a and 2b). There are flow textures adjacent to olivine grains (Fig. 1b). These textures were not primary nor were produced by brecciation and solid-state recrystallization. These textures were likely to have formed by remelting of precursor olivine diogenites. Larger olivine grains and aggregates, and chromite grains are fragments and lithic clasts (or relicts) of the precursor rocks. The pyroxene-rich matrix crystallized from impact melt. Upon heating, low-Ca pyroxene is the earliest phase to melt, and olivine and chromite are the last at $>1600{ }^{\circ} \mathrm{C}$ (Stolper 1977; Righter and Drake 1997). The irregular and rounded shape resulted from resorption, and pyroxene veins and flow textures formed by violent mixing during impact melting. Small crystals around large olivines and chromites grew from the walls as favorable nucleation sites. Pyroxene grain size differences imply different cooling rates at different sites

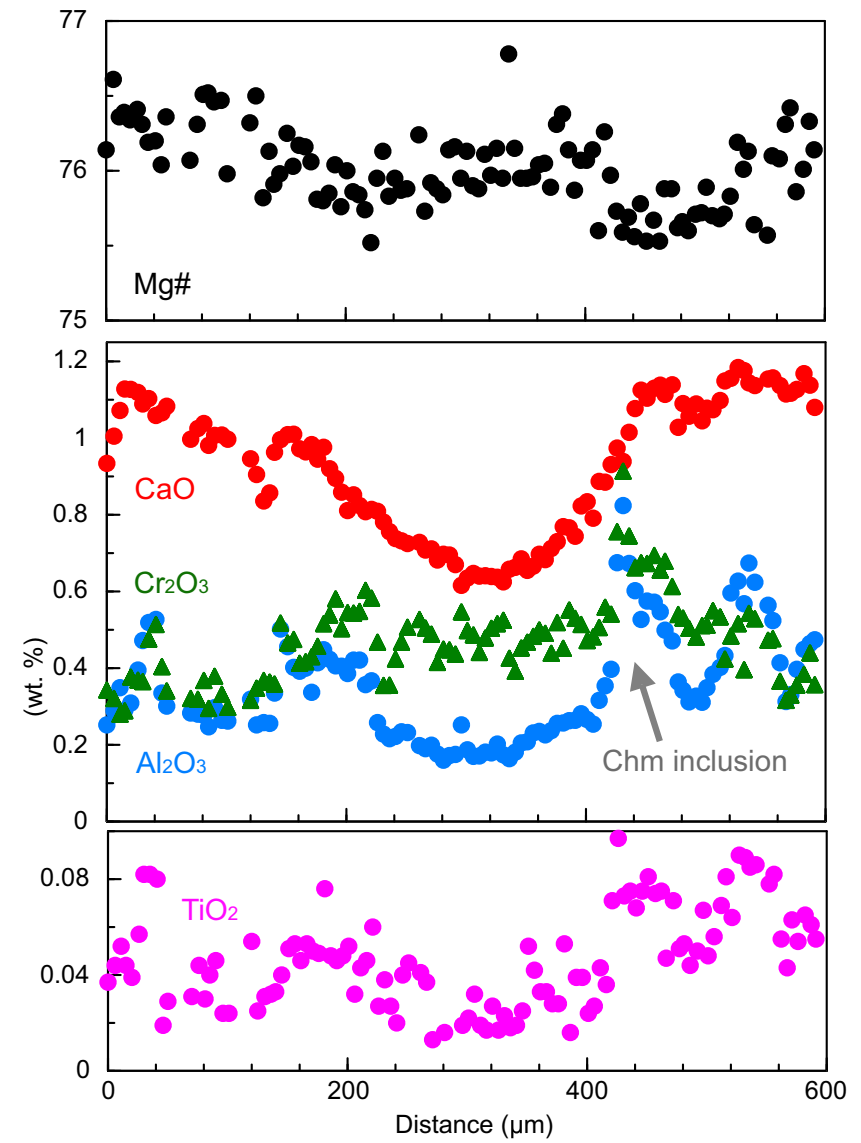

Fig. 6. Compositional profiles in pyroxene. $\mathrm{Mg \#} \mathrm{(=} \mathrm{molar}$ $\mathrm{Mg} /[\mathrm{Mg}+\mathrm{Fe}] \times 100)$ values show no resolvable zoning. Minor elements of pyroxene show normal igneous zoning indicating that these pyroxenes crystallized from a melt. Peaks of $\mathrm{Al}_{2} \mathrm{O}_{3}$ and $\mathrm{Cr}_{2} \mathrm{O}_{3}$ are from small chromite (Chm) inclusions. The locations of these profiles are shown in Fig. $2 \mathrm{f}$.

or differences in nucleation densities. These lines of petrologic evidence indicate that NWA 5480 is an impact-melt breccia.

Similar textures displayed by olivine and chromite in NWA 5480 are also observed in ordinary chondrite impact-melt breccias (Yamaguchi et al. 1998, 1999) (Fig. 8). Such similarities are not surprising because major element compositions (except some minor elements such as $\mathrm{Na}, \mathrm{K}$ ) of silicate portions of ordinary chondrites resemble olivine diogenites. Thus, crystallization (melting) sequences upon cooling (heating) near the liquidus are similar between ordinary chondrites and diogenites. Both examples of impact-melt breccias experienced almost total melting, with the exception of olivine and chromite. In contrast, cooling rates in the two examples must have been very different, as indicated by the distinct size distribution of pyroxene found in the matrix and also the $\mathrm{Ca}$ content in olivine. Beck et al. (2012) found olivine-rich impact-melt breccia clasts in the PCA 02 howardite group. However, the pyroxene 
Table 1. Chemical compositions of minerals in NWA 5480.

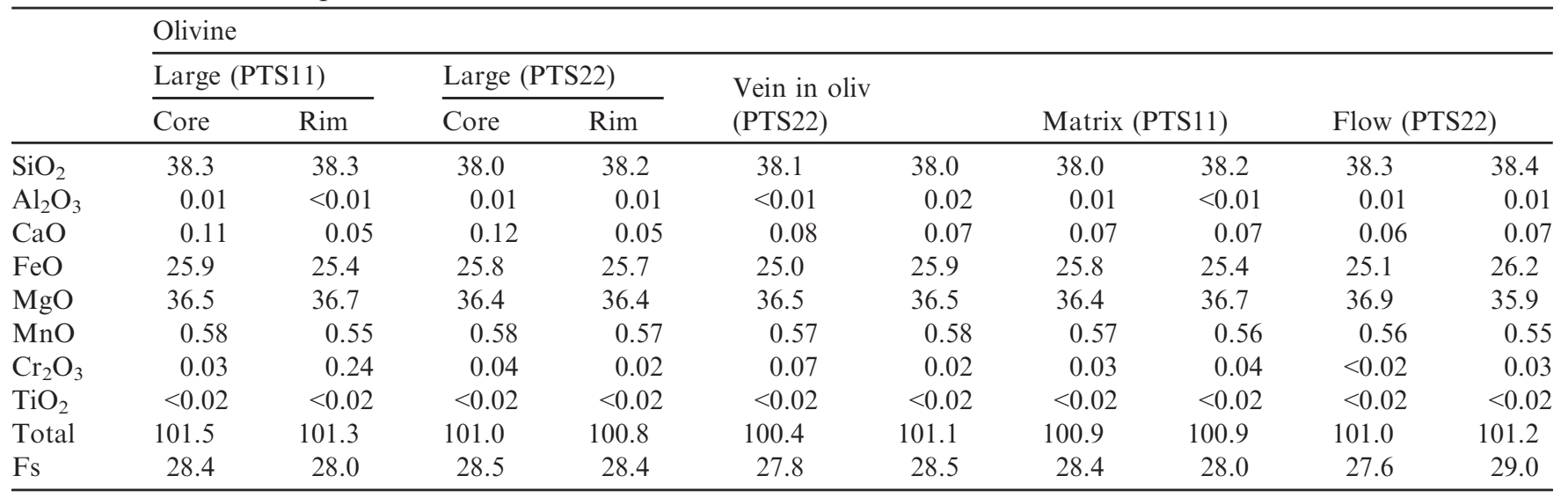

\begin{tabular}{|c|c|c|c|c|c|c|}
\hline & Chron & & & & & \\
\hline & Large & & & & Large & \\
\hline & Core & Rim & Vein & Vein & Core & Rim \\
\hline $\mathrm{SiO}_{2}$ & 0.02 & 0.04 & 0.06 & 0.03 & 0.05 & 0.08 \\
\hline $\mathrm{Al}_{2} \mathrm{O}_{3}$ & 8.30 & 7.47 & 7.15 & 7.82 & 7.74 & 7.59 \\
\hline $\mathrm{CaO}$ & 0.01 & 0.01 & $<0.01$ & $<0.01$ & $<0.01$ & $<0.01$ \\
\hline $\mathrm{FeO}$ & 25.0 & 25.8 & 25.3 & 25.1 & 27.2 & 27.7 \\
\hline $\mathrm{MgO}$ & 6.00 & 5.30 & 5.66 & 5.80 & 4.74 & 4.26 \\
\hline $\mathrm{MnO}$ & 0.47 & 0.52 & 0.55 & 0.60 & 0.62 & 0.64 \\
\hline $\mathrm{Cr}_{2} \mathrm{O}_{3}$ & 57.8 & 58.6 & 59.4 & 58.9 & 58.1 & 57.3 \\
\hline $\mathrm{TiO}_{2}$ & 0.73 & 0.79 & 0.68 & 0.72 & 0.84 & 0.78 \\
\hline $\mathrm{V}_{2} \mathrm{O}_{3}$ & 0.62 & 0.57 & 0.63 & 0.58 & 0.70 & 0.70 \\
\hline Total & 98.4 & 98.5 & 98.8 & 99.0 & 99.2 & 98.3 \\
\hline Usp & 2.0 & 2.1 & 1.8 & 1.9 & 2.2 & 2.1 \\
\hline $\mathrm{Sp}$ & 17.3 & 15.6 & 14.9 & 16.2 & 16.2 & 16.1 \\
\hline Chm & 80.8 & 82.2 & 83.3 & 81.9 & 81.6 & 81.7 \\
\hline $\mathrm{Fe} \#$ & 70.1 & 73.2 & 71.5 & 70.8 & 76.28 & 78.47 \\
\hline
\end{tabular}

\begin{tabular}{|c|c|c|c|c|c|c|c|c|}
\hline & \multicolumn{8}{|c|}{ Pyroxene } \\
\hline & \multicolumn{2}{|c|}{ Matrix (PTS11) } & \multicolumn{2}{|c|}{ Matrix (PTS22) } & \multirow{2}{*}{\multicolumn{2}{|c|}{$\begin{array}{l}\text { Vein in Chm } \\
\text { (PTS22) }\end{array}$}} & \multirow{2}{*}{\multicolumn{2}{|c|}{$\begin{array}{l}\text { Vein in Oliv } \\
\text { (PTS22) }\end{array}$}} \\
\hline & Core & Rim & High-Mg & Low-Mg & & & & \\
\hline $\mathrm{SiO}_{2}$ & 55.3 & 55.3 & 55.3 & 55.0 & 55.3 & 55.2 & 55.2 & 54.8 \\
\hline $\mathrm{Al}_{2} \mathrm{O}_{3}$ & 0.27 & 0.40 & 0.28 & 0.45 & 0.48 & 0.29 & 0.40 & 0.67 \\
\hline $\mathrm{CaO}$ & 0.69 & 1.10 & 0.86 & 1.31 & 1.30 & 2.06 & 1.15 & 1.25 \\
\hline $\mathrm{FeO}$ & 15.3 & 15.5 & 14.8 & 16.3 & 14.6 & 14.8 & 14.9 & 15.5 \\
\hline $\mathrm{MgO}$ & 27.4 & 27.1 & 27.1 & 26.7 & 27.6 & 26.9 & 27.3 & 27.0 \\
\hline $\mathrm{MnO}$ & 0.52 & 0.54 & 0.54 & 0.54 & 0.49 & 0.53 & 0.53 & 0.52 \\
\hline $\mathrm{Cr}_{2} \mathrm{O}_{3}$ & 0.52 & 0.51 & 0.49 & 0.50 & 0.54 & 1.09 & 0.47 & 0.75 \\
\hline $\mathrm{TiO}_{2}$ & 0.04 & 0.05 & 0.06 & 0.06 & 0.08 & 0.06 & 0.04 & 0.08 \\
\hline Total & 100.1 & 100.5 & 99.4 & 100.8 & 100.4 & 100.9 & 99.9 & 100.6 \\
\hline Wo & 1.4 & 2.2 & 1.7 & 2.6 & 2.5 & 4.0 & 2.3 & 2.4 \\
\hline En & 75.1 & 74.1 & 75.3 & 72.6 & 75.2 & 73.3 & 74.9 & 73.7 \\
\hline Fs & 23.6 & 23.7 & 23.0 & 24.8 & 22.3 & 22.6 & 22.9 & 23.8 \\
\hline
\end{tabular}

$\mathrm{Fe} \#=\operatorname{molar} \mathrm{Fe} /(\mathrm{Fe}+\mathrm{Mg}) \times 100$.

portion is much finer grained, and the degrees of igneous zoning in olivine are much smaller, indicating rapid cooling after melting.
Relative enrichment of $\mathrm{Ca}$ in olivine can be explained by high-temperature annealing or represents an indigenous feature formed during primary crystallization at depth. The 


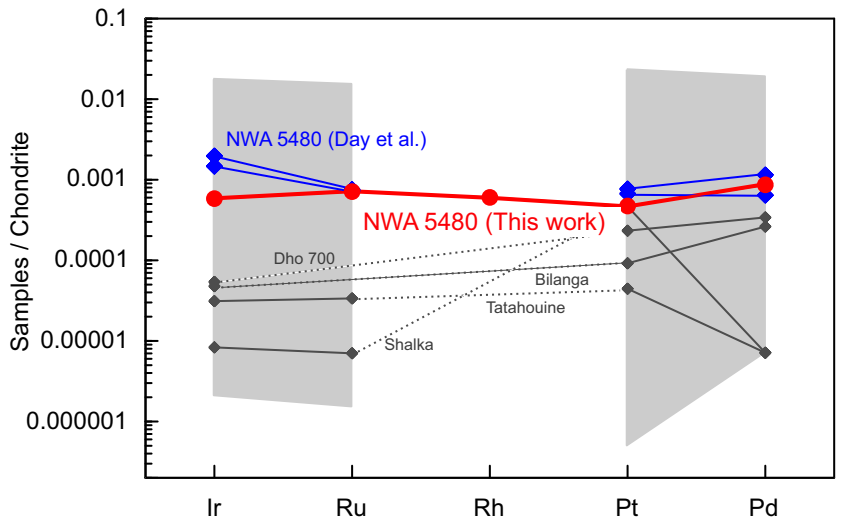

Fig. 7. Chondrite-normalized PGE patterns from a pyroxenerich portion in NWA 5480 (this work), NWA 5480 of Day et al. (2012) and other diogenites (light blue area, Dale et al. 2012; Day et al. 2012). Also shown are four diogenites (Bilanga, Dho 700, Shalka, and Tatahouine) with no evidence of meteoritic contamination (Dale et al. 2012). NWA 5480 has high PGE abundances $\left(5-9 \times 10^{-4} \mathrm{CI}\right)$ and shows a relatively flat (unfractionated) pattern. Chondrite data are from Anders and Grevesse (1989).

Table 2. Bulk PGE abundances of NWA 5480.

\begin{tabular}{lllll}
\hline & \multicolumn{2}{l}{ NWA 5480 } & \multicolumn{2}{l}{$\begin{array}{l}\text { Diogenite } \\
\text { Range }^{\mathrm{a}}\end{array}$} \\
\cline { 2 - 4 }$(\mathrm{ppb})$ & This work & \multicolumn{2}{l}{ Day et al. } & $0.001-10.71$ \\
$\mathrm{Ru}$ & $0.5076 \pm 0.0262$ & 0.5169 & 0.5386 & $0.004-10.68$ \\
$\mathrm{Rh}$ & $0.0809 \pm 0.0024$ & & & \\
$\mathrm{Pd}$ & $0.4849 \pm 0.0214$ & 0.6433 & 0.3604 & 0.004 \\
$\mathrm{Ir}$ & $0.2805 \pm 0.0095$ & 0.7083 & 0.9492 & $0.003-8.33$ \\
$\mathrm{Pt}$ & $0.4675 \pm 0.0166$ & 0.7617 & 0.6659 & $0.001-22.49$ \\
\hline
\end{tabular}

${ }^{\mathrm{a}}$ Total range of PGE abundances in diogenites (Dale et al. 2012; Day et al. 2012)

shape and width of $\mathrm{Ca}$ zoning profiles near the olivine rim are similar to those of the pallasitic olivines having similar major element compositions. This indicates that NWA 5480 cooled at several tens of ${ }^{\circ} \mathrm{C} /$ year, corresponding to burial depths several tens $\mathrm{m}$ (Miyamoto 1997), much shallower than the inferred thickness of the Vestan crust $\sim 80 \mathrm{~km}$ (Jutzi et al. 2013; Clenet et al. 2014). This is also consistent with preservation of minor element zoning in pyroxene (Yamaguchi et al. 2011). The presence of such zoning indicates that NWA 5480 cooled more rapidly than did many basaltic eucrites (e.g., Yamaguchi et al. 1996; Takeda 1997). The rapid cooling evidenced by the minerals argue against a deep origin for this meteorite (Irving et al. 2009).

The pyroxene-rich portions (impact-melt matrix) in NWA 5480 contain a significant amount of PGE (Fig. 7; Table 2). The results are similar to those of unspecified lithology (Day et al. 2012). The PGE patterns are unfractionated and point to a contamination of ca. $0.1 \mathrm{wt} \%$ chondritic materials. These facts suggest that incorporation of PGE took place after major differentiation. Therefore, the petrological and geochemical evidence strongly supports the possibility that NWA 5480 is an impact-melt breccia.

However, recently, Tkalcec et al. (2013) and Tkalcec and Brenker (2014) argued that the olivine-rich portion of NWA 5480 was plastically deformed under solid-state conditions in a temperature-pressure-strain rate regime where $\{0 \mathrm{k} 1\}[100]$ pencil-glide in olivine is the most active mechanism and was typically generated by mantle shear. It might be possible that olivine clasts were derived from the Vestan mantle rock, and preserved the deformation features during brecciation, impact melting, and perhaps recrystallization. However, lattice preferred orientation (LPO) observed in olivine is not produced by just one process.

The range of strain rates that can be achieved by large impacts varies from $\sim 1-10^{8} \mathrm{~s}^{-1}$ (e.g., Spray 2010). Also, slower and gentle processes caused by grazing impacts of protoplanets (e.g., Vesta) have been proposed (Asphaug et al. 2006). Such large impact events would have caused shear in deep hot crust or upper mantle (i.e., Rheasilvia $\sim 500 \mathrm{~km}$ in diameter). Also, olivines from impact melted stony-iron meteorites (mesosiderites) display similar features (Carter et al. 1968). Mesosiderites were derived from a body which experienced a catastrophic impact event (Scott et al. 2001). Thus, further studies are required to resolve this issue. All other petrological and geochemical observations, with possible exception of LPO in olivine, favor an impact origin for NWA 5480.

As already discussed, the cooling rate of NWA 5480 was several tens of ${ }^{\circ} \mathrm{C} /$ year, corresponding to burial depths several tens $\mathrm{m}$. The minimum thickness of impactmelt sheet would have been several tens $\mathrm{m}$. Warren et al. (1996) and Keil et al. (1997) estimated the volume of impact melts on an asteroid relevant to the size of Vesta using semi-empirical methods. According to their methods, an impact crater with diameter $>$ a few hundreds $\mathrm{km}$ is needed to produce impact-melt sheet $>$ several tens $m$ in thickness assuming a cylindrical homogeneous melt sheet inside the crater. We suggest that NWA 5480 was derived from impact melts from a very large crater. NWA 5480 displays REE patterns with the same heavy REE enrichments and Eu anomalies as other diogenites (Barrat et al. 2010; Day et al. 2012). Thus, the target was an area where olivine and orthopyroxene-rich rocks are largely exposed. However, there are no such areas on Vesta except minor olivine spots (Ammannito et al. 2013). It is likely that NWA 5480 sampled a part of large impact-melt sheet (>several tens $m$ thick) formed by melting of deep crustal materials rich in olivine and orthopyroxene. One of the best candidates is the Rheasilvia basin $(\sim 500 \mathrm{~km}$ diameter $)$ where orthopyroxene-rich materials were observed in the crater floor (McSween et al. 2013). Petrological and geochemical 

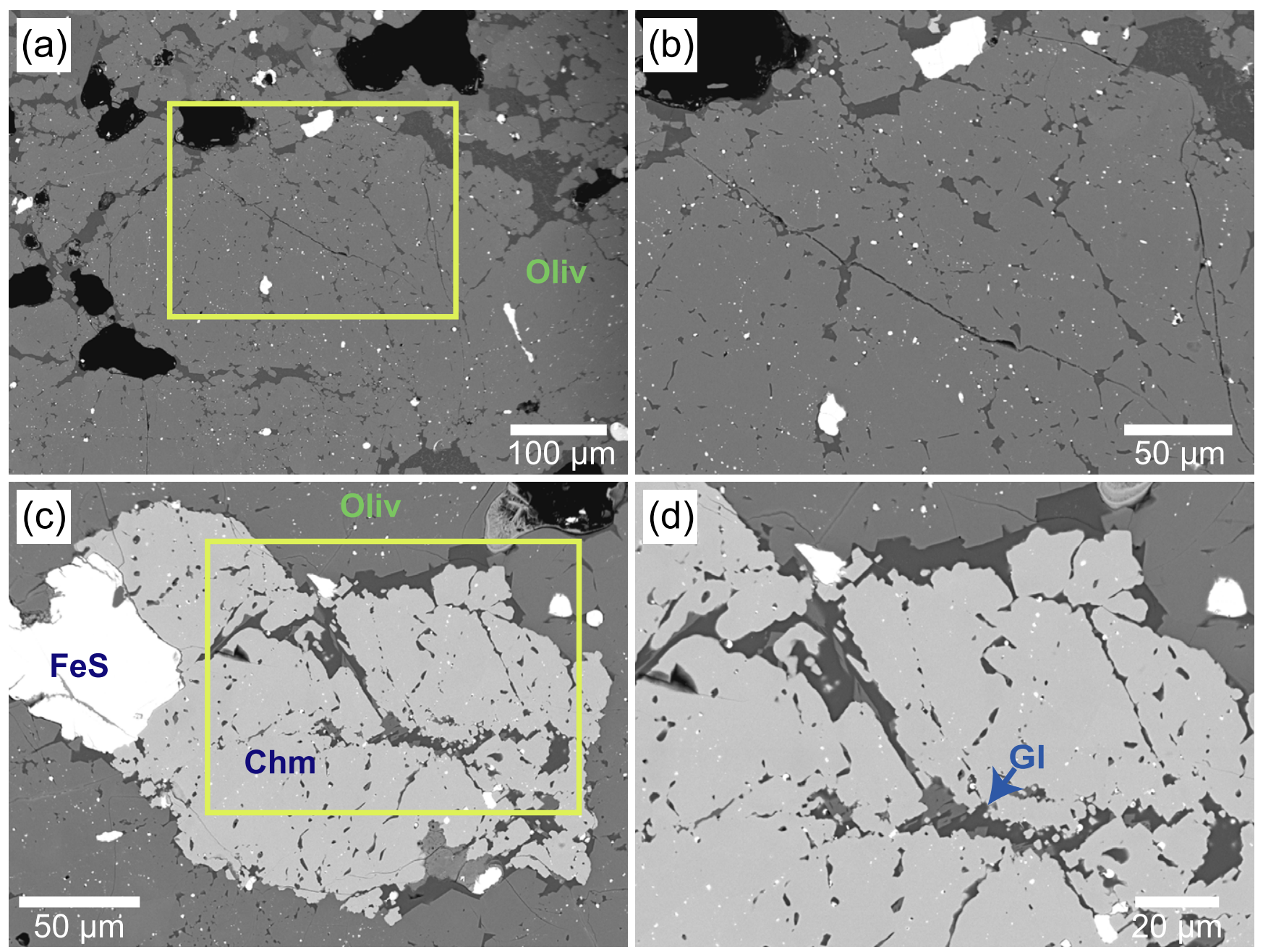

Fig. 8. BEIs of a LL chondrite melt breccia (Y-790960) (Yamaguchi et al. 1998). a) Relict olivine (Oliv). b) Enlarged view of a box in (a). c) Relict chromite (Chm). d) Enlarged view of a box in (c). Relict olivine and chromite grains have fractures intruded by feldspathic glass $(\mathrm{Gl})$ and pyroxene. Also, these relict grains are surrounded by newly formed euhedral crystals.

evidence from NWA 5480 provides clues to the early intense bombardment history of the parent body, Vesta.

Acknowledgments - We thank R. Greenwood, P. Claeys, and M. Kimura for discussions, and A. W. Beck, an anonymous reviewer, and A. Ruzicka for the constructive reviews. This work is partly supported by a Grant-in-Aid for Scientific Research from the Ministry of Education, Science, and Technology, Japan, and NIPR Research Project Funds, KP-6.

\section{Editorial Handling-Dr. Alex Ruzicka}

\section{REFERENCES}

Ammannito E., De Sanctis M. C., Palomba E., Longobardo A., Mittlefehldt D. W., McSween H. Y., Marchi S., Capria M. T., Capaccioni F., Frigeri A., Pieters C. M., Ruesch O., Tosi F., Zambon F., Carraro F., Fonte S., Hiesinger H.,
Magni G., McFadden L. A., Raymond C. A., Russell C. T., and Sunshine J. M. 2013. Olivine in an unexpected location on Vesta's surface. Nature 504:122-125.

Anders E. and Grevesse N. 1989. Abundance of the elements: Meteoritic and solar. Geochimica et Cosmochimica Acta 53:197-214.

Asphaug E., Agnor C. B., and Willisams Q. 2006. Hit-and-run planetary collisions. Nature 439:155-160.

Barrat J. A. and Yamaguchi A. 2014. Comment on "The origin of eucrites, diogenites, and olivine diogenites: Magma ocean crystallization and shallow magma processes on Vesta" by B. E. Mandler and L. T. ElkinsTanton. Meteoritics \& Planetary Science 49:468-472.

Barrat J. A., Yamaguchi A., Benoit M., Cotten J., and Bohn M. 2008. Geochemistry of diogenites: Still more diversity in their parental melts. Meteoritics \& Planetary Science 43:1759-1775.

Barrat J. A., Yamaguchi A., Zanda B., Bollinger C., and Bohn M. 2010. Relative chronology of crust formation on asteroid Vesta: Insights from the geochemistry of diogenites. Geochimica et Cosmochimica Acta 74: 6218-6231. 
Beck A. W. and McSween H. Y. 2010. Diogenites as polymict breccias composed of orthopyroxene and harzburgite. Meteoritics \& Planetary Science 45:850-872.

Beck A. W., Welten K. C., McSween H. Y. Jr., Viviano C. E., and Caffee M. W. 2012. Petrologic textural diversity among PCA 02 howardite group, one of the largest pieces of the Vestan surface. Meteoritics \& Planetary Science 47:947-969.

Binzel R. P. and Xu S. 1993. Chips off asteroid 4 Vesta: Evidence for the parent body of basaltic achondrite meteorites. Science 260:186-191.

Carter N. L., Raleigh C. B., and DeCarli P. S. 1968. Deformation of olivine in stony meteorites. Journal Geophysical Research 73:5439-5461.

Clenet H., Jutzi M., Barrat J.-A., Asphaug E., Benz W., and Gillet P. 2014. A deep Moho in "small planet" Vesta. Nature 511:303-306.

Dale C. W., Burton K. W., Greenwood R. C., Gannoun A., Wade J., Wood B. J., and Pearson D. G. 2012. Late accretion on the earliest planetesimals revealed by the highly siderophile elements. Science 336:72-75.

Day J. M., Walker R. J., Qin L., and Rumble D. III. 2012. Late accretion as a natural consequence of planetary growth. Nature Geoscience 5:614-617.

De Sanctis M. C., Ammannito E., Capria M. T., Tosi F., Capaccioni F., Zambon F., Carraro F., Fonte S., Frigeri A., Jaumann R., Magni G., Marchi S., McCord T. B., McFadden L. A., McSween H. Y., Mittlefehldt D. W., Nathues A., Palomba E., Pieters C. M., Raymond C. A., Russell C. T., Toplis M. J., and Turrini D. 2012. Spectroscopic characterization of mineralogy and its diversity across Vesta. Science 336:697-700.

Fowler G. W., Papike J. J., Shearer C. K., and Spilde M. N. 1994. Diogenites as asteroidal cumulates. Insights from orthopyroxene major and minor element chemistry. Geochimica et Cosmochimica Acta 58:3921-3929.

Greenwood R. C., Barrat J.-A., Yamaguchi A., Franchi I. A., Scott E. R. D., Bottke W. F., and Gibson J. M. 2014. The oxygen isotope composition of diogenites: Evidence for early global melting on a single, compositionally diverse, HED parent body. Earth and Planetary Science Letters 390:165-174.

Irving A. J., Bunch T. E., Kuehner S. M., Wittke J. H., and Rumble D. III. 2009. Peridotites related to 4 Vesta: Deep crustal igneous cumulates and mantle samples (abstract \#2466). 40th Lunar and Planetary Science Conference. CD-ROM.

Jackson E. D. 1961. Primary textures and mineral associations in the ultramafic zone of the Stillwater complex, Montana. Geological Survey Professional Paper 358.

Jutzi M., Asphaug E., Gillet P., Barrat J.-A., and Benz W. 2013. The structure of the asteroid 4 Vesta as revealed by models of planet-scale collisions. Nature 494:207-210.

Keil K., Stöffler D., Love S. G., and Scott E. R. D. 1997. Constraints on the role of impact heating and melting in asteroids. Meteoritics \& Planetary Science 32:349-363.

Mandler B. E. and Elkins-Tanton L. T. 2013. The origin of eucrites, diogenites, and olivine diogenites: Magma ocean crystallization and shallow magma chamber processes on Vesta. Meteoritics \& Planetary Science 48:2333-2349.

McCord T. B., Adams J. B., and Johnson T. V. 1970. Asteroid Vesta: Spectral reflectivity and compositional implications. Science 168:1445-1447.

McSween H. Y., Ammannito E., Reddy V., Prettyman T. H., Beck A. W., De Sanctis M. C., Nathues A., Le Corre L.,
O'Brien D. P., Yamashita N., McCoy T. J., Mittlefehldt D. W., Toplis M. J., Schenk P., Palomba E., Turrini D., Tosi F., Zambon F., Longobardo A., Capaccioni F., Raymond C. A., and Russell C. T. 2013. Composition of the Rheasilvia basin, a window into Vesta's interior. Journal of Geophysical Research 118:335-346.

Mittlefehldt D. W. 1994. The genesis of diogenites and HED parent body petrogenesis. Geochimica et Cosmochimica Acta 58:1537-1552.

Mittlefehldt D. W. 2015. Asteroid (4) Vesta: I. The howarditeeucrite-diogenite (HED) clan of meteorites. Chemie der Erde - Geochemistry, doi:10.1016/j.chemer.2014.08.002

Miyamoto M. 1997. Chemical zoning of olivine in several pallasites. Journal of Geophysical Research 102:2161321618.

Righter K. and Drake M. J. 1997. A magma ocean on Vesta: Core formation and petrogenesis of eucrites and diogenites. Meteoritics \& Planetary Science 32:929-944.

Russell C. T., Raymond C. A., Coradini A., McSween H. Y., Zuber M. T., Nathues A., De Sanctis M. C., Jaumann R., Konopliv A. S., Preusker F., Asmar S. W., Park R. S., Gaskell R., Keller H. U., Mottola S., Roatsch T., Scully J. E. C., Smith D. E., Tricarico P., Toplis M. J., Christensen U. R., Feldman W. C., Lawrence D. J., McCoy T. J., Prettyman T. H., Reedy R. C., Sykes M. E., and Titus T. N. 2012. Dawn at Vesta: Testing the protoplanetary paradigm. Nature 336:684-686.

Schenk P., O'Brien D. P., Marchi S., Gaskell R., Preusker F., Roatsch T., Jaumann R., Buczkowski D., McCord T., McSween H. Y., Williams D., Yingst A., Raymond C., and Russell C. 2012. The geologically recent giant impact basins at Vesta's south pole. Science 336:694-697.

Scott E. R. D., Haack H., and Love S. G. 2001. Formation of mesosiderites by fragmentation and reaccretion of a large differentiated asteroid. Meteoritics \& Planetary Science 36:869-881.

Shearer C. K., Burger P., and Papike J. J. 2010. Petrogenetic relationships between diogenites and olivine diogenites: Implication for magmatism on the HED parent body. Geochimica et Cosmochimica Acta 74:4865-4880.

Shirai N., Nishino T., Li X., Amakawa H., and Ebihara M. 2003. Precise determination of PGE in a GSJ reference sample JP-1 by ID-ICPMS after nickel sulfide fire assay preconcentration. Geochemical Journal 37:531-536.

Spray J. G. 2010. Frictional melting processes in planetary materials: From hypervelocity impact to earthquakes. Annual Review of Earth and Planetary Sciences 38: 221-254.

Stolper E. 1977. Experimental petrology of eucrite meteorites. Geochimica et Cosmochimica Acta 41:587-611.

Takeda H. 1997. Mineralogical records of early planetary processes on the howardite, eucrite, diogenite parent body with reference to Vesta. Meteoritics \& Planetary Science 32:841-853.

Tkalcec B. J. and Brenker F. 2014. Plastic deformation of olivine-rich diogenites and implications for mantle processes on the diogenite parent body. Meteoritics \& Planetary Science 49:1202-1213.

Tkalcec B. J., Golabek G. J., and Brenkder F. E. 2013. Solidstate plastic deformation in the dynamic interior of a differentiated asteroid. Nature Geoscience 6:93-97.

Warren P. H., Claeys P., and Cedillo-Pardo E. 1996. Megaimpact melt petrology (Chicxulub, Sudbury, and the Moon): Effects of scale and other factors on potential for 
fractional crystallization ad development of cumulates. Geological Society of America Special Paper 307:105-124.

Yamaguchi A., Taylor G. J., and Keil K. 1996. Global crustal metamorphism of the eucrite parent body. Icarus 124:97-112.

Yamaguchi A., Scott E. R. D., and Keil K. 1998. Origin of unusual impact melt rocks, Yamato-790964 and -790143 LL-chondrites. Antarctic Meteorite Research 11:18-31.
Yamaguchi A., Scott E. R. D., and Keil K. 1999. Origin of a unique impact-melt rock-The L-chondrite Ramsdorf. Meteoritics \& Planetary Science 34:49-59.

Yamaguchi A., Barrat J. A., Ito M., and Bohn M. 2011. Posteucritic magmatism on Vesta: Evidence from petrology and thermal history of diogenites. Journal of Geophysical Research: Planets 116:1991-2012. 